\title{
Psychosocial Nursing Care With Helplessness Problems in Stroke Patients: Case Study
}

\section{Felix Jekki M. Berutu}

\section{felixjekkiberutu@gmail.com}

\section{BAB I}

\section{PENDAHULUAN}

\subsection{Latar Belakang}

Stroke merupakan penyakit atau gangguan fungsional otak berupa kelumpuhan saraf (deficit neurologic) akibat terhambatnya aliran darah ke otak. Stroke adalah sindrom yang terdiri dari tanda dan/atau gejala hilangnya fungsi sistem saraf pusat fokal (atau global) yang berkembang cepat (dalam detik atau menit). Gejala-gejala ini berlangsung lebih dari 24 jam atau menyebabkan kematian, selain menyebabkan kematian stroke juga akan mengakibatkan dampak untuk kehidupan. Dampak stroke diantaranya, ingatan jadi terganggu dan terjadi penurunan daya ingat, menurunkan kualitas hidup penderita juga kehidupan keluarga dan orang-orang di sekelilingnya, mengalami penurunan kualitas hidup yang lebih drastis kecacatan fisik maupun mental pada usia produktif dan usia lanjut dan kematian dalam waktu singkat (Junaidi, 2016).

Stroke masih menjadi masalah kesehatan yang utama karena merupakan penyebab kematian kedua di dunia. Sementara itu, di Amerika Serikat stroke sebagai penyebab kematian ketiga terbanyak setelah penyakit kardiovaskuler dan kanker. Sekitar 795.000 orang di Amerika Serikat mengalami stroke setiap tahunnya, sekitar 610.000 mengalami serangan stroke yang pertama. Stroke juga merupakan penyebab 134.000 kematian pertahun (Junaidi, 2016)

Penyakit stroke sering dianggap sebagai penyakit yang didominasi oleh orang tua. Dulu, stroke hanya terjadi pada usia tua mulai 60 tahun, namun sekarang mulai usia 40 tahun seseorang sudah memiliki risiko stroke, meningkatnya penderita stroke usia muda lebih disebabkan pola hidup, terutama pola makan tinggi kolesterol. Berdasarkan pengamatan di berbagai rumah sakit, justru stroke di usia produktif sering terjadi akibat kesibukan kerja 
yang menyebabkan seseorang jarang olahraga, kurang tidur, dan stres berat yang juga jadi faktor penyebab (Diani, 2017)

ketidakberdayaan adalah faktor yang memengaruhi perilaku bunuh diri pada pasien psikiatri rawat inap. juga menemukan bahwa percobaan bunuh diri sebelumnya, tingkat depresi, ketidakberdayaan, dan impulsivitas merupakan faktor risiko yang memprediksi meningkatnya ide-ide bunuh diri atau perilaku bunuh diri pada pasien psikiatri yang telah menjalani pengobatan rawat inap. juga menemukan bahwa ketidakberdayaan memprediksi percobaan bunuh diri pada pasien dengan gangguan psikosis. Namun penelitian tersebut belum mewakili semua fenomena karena mengkhususkan pada pasien psikiatri rawat inap dan juga pasien psikosis

Kecemasan merupakan suatu respon psikologis maupun fisiologis individu terhadap suatu keadaan yang tidak menyenangkan, atau reaksi atas situasi yang dianggap mengancam( Hulu \& Pardede, 2016)

Survei awal yang dilakukan dikelurahan dwi kora jalan Amal luhur maka ditemukan pasien dengan kecemasan akibat Bells Palsy yang bernama Tn.S dengan kecemasan di Amal Luhur Kec Medan Helvetia

\subsection{Rumusan masalah}

Berdasakan uraian latar belakang maka penulis membuat rumusan masalah sebagai berikut: Asuhan Keperawatan Pada Tn. S dengan ketidakberdayaan di Simalingkar Kec. Medan Tuntungan.

\subsection{Tujuan}

\subsubsection{Tujuan Umum}

Untuk memberikan asuhan keperawatan Pada Tn. S dengan masalah kecemasan

\subsubsection{Tujuan Khusus}

1. Mahasiwa mampu melakukan Pengkajian pada Tn. S Dengan masalah kecemasan

2. Mahasiswa mampu menegakan diagnosa pada Tn. S Dengan masalah kecemasan

3. Mahasiswa mampu membuat intervensi pada Tn. S Dengan masalah kecemasan

4. Mahasiswa mampu melakukan implementasi pada Tn. S Dengan masalah kecemasan

5. Mahasiwa mampu membuat evaluasi pada Tn. S Dengan masalah kecemasan 


\section{BAB 2}

\section{TINJAUAN PUSTAKA}

\subsection{Konsep Stroke}

\subsubsection{Definisi Stroke}

Stroke non hemoragik yaitu tersumbatnya pembuluh darah yang menyebabkan aliran darah ke otak sebagian atau keseluruhan terhenti. Tidak terjadi perdarahan namun terjadi iskemia yang menimbulkan hipoksia dan selanjutnya dapat timbul edema sekunder (Wijaya \& Putri, 2017)

Stroke non hemoragik adalah tanda klinis disfungsi atau kerusakan jaringan otak yang disebabkan kurangnya aliran darah ke otak sehingga mengganggu kebutuhan darah dan oksigen di jaringan otak. Stroke nonhemoragik dapat disebabkan oleh trombosis dan emboli, sekitar 80-85\% menderita penyakit stroke non-hemoragik dan $20 \%$ persen sisanya adalah stroke hemoragik yang dapat disebabkan oleh pendarahan intraserebrum hipertensi dan perdarahan subarachnoid (Wilson \& Price, 2016)

\subsubsection{Anatomi dan Fisiologi}

Otak Otak merupakan pusat kendali fungsi tubuh yang rumit dengan sekitar 100 millar sel saraf, walaupun berat total otak hanya sekitar 2,5\% dari berat tubuh, 70 $\%$ oksigen dan nutrisi yang diperlukan tubuh ternyata digunakan oleh otak. Berbeda dengan otak dan jaringan lainya. Otak tidak mampu menyimpan nutrisi agar bisa berfungsi, otak tergantung dari pasokan aliran darah, yang secara kontinyu membawa oksigen dan nutrisi. Pada dasarnya otak terdiri dari tiga bagian besar dengan fungsi tertentu yaitu:

1. Otak besar, Otak besar yaitu bagian utama otak yang berkaitan dengan fungsi intelektual yang lebih tinggi, yaitu fungsi bicara, integritas informasi sensori ( rasa ) dan kontrol gerakan yang halus. Pada otak besar ditemukan beberapa lobus yaitu, lobus frontalis, lobus parientalis, lobus temporalis, dan lobus oksipitalis.

2. Otak kecil, Terletak dibawah otak besar berfungsi untuk koordinasi gerakan dan keseimbangan.

3. Batang otak, Berhubungan dengan tulang belakang, mengendalikan berbagai fungsi tubuh termasuk koordinasi gerakan mata, menjaga keseimbangan, serta 
mengatur pernafasan dan tekanan darah. Batang otak terdiri dari, otak tengah, pons dan medula oblongata.

\subsubsection{Etiologi}

Stroke non hemoragik terjadi karena tersumbatnya pembuluh darah yang menyebabkan aliran darah ke otak sebagian atau keseluruhan terhenti. Hal ini disebabkan oleh aterosklerosis yaitu penumpukan kolesterol pada dinding pembuluh darah atau bekuan darah yang telah menyumbat suatu pembuluh darah ke otak Stroke non hemoragik terjadi pada pembuluh darah yang mengalami sumbatan sehingga menyebabkan berkurangnya aliran darah pada jaringan otak, thrombosis otak, aterosklerosis dan emboli serebral yang merupakan penyumbatan pembuluh darah yang timbul akibat pembentukan plak sehingga terjadi penyempitan pembuluh darah yang 11 dikarenakan oleh penyakit jantung, diabetes, obesitas, kolesterol, merokok, stress, gaya hidup, rusak atau hancurnya neuron motorik atas (upper motor neuron) dan hipertensi (Pudiastuti, 2016)

\subsubsection{Patofisiologi}

Stroke non hemoragik disebabkan oleh trombosis akibat aterosklerosis yang memberi vaskularisasi pada otak atau oleh emboli dari pembuluh darah diluar otak yang tersangkut di arteri otak. Saat terbentuknya plak fibrosis (ateroma) dilokasi yang terbatas seperti di tempat percabangan arteri. Trombosit selanjutnya melekat pada permukaan plak bersama dengan fibrin, perlekatan trombosit secara perlahan akan memperbesar ukuran plak sehingga terbentuk thrombus. Trombus dan emboli di dalam pembuluh darah akan terlepas dan terbawa hingga terperangkap dalam pembuluh darah distal, lalu menyebabkan pengurangan aliran darah yang menuju ke otak sehingga sel otak akan mengalami kekurangan nutrisi dan juga oksigen, sel otak yang mengalami kekurangan oksigen dan glukosa akan menyebabkan asidosis atau tingginya kadar asam di dalam tubuh lalu asidosis akan mengakibatkan natrium klorida, dan air masuk ke dalam sel otak dan kalium meninggalkan sel otak sehingga terjadi edema setempat. Kemudian kalium akan masuk dan memicu serangkaian radikal bebas sehingga terjadi perusakan membran sel lalu mengkerut dan tubuh mengalami defisit neurologis lalu mati (Esther, 2015) 


\subsubsection{Komplikasi}

Komplikasi stroke meliputi hipoksia serebral, penurunan aliran darah serebral dan luasnya area cedera yang dapat mengakibatkan perubahan pada aliran darah serebral sehingga ketersediaan oksigen ke otak menjadi berkurang dan akan menimbulkan kematian jaringan otak (Bararah, \& Jauhar, 2013). Komplikasi Stroke Menurut pada pasien stroke yang berbaring lama dapat terjadi masalah fisik dan emosional diantaranya:

1. Bekuan darah (Trombosis) Mudah terbentuk pada kaki yang lumpuh menyebabkan penimbunan cairan, pembengkakan (edema) selain itu juga dapat menyebabkan embolisme paru yaitu sebuah bekuan yang terbentuk dalam satu arteri yang mengalirkan darah ke paru.

2. Dekubitus Bagian tubuh yang sering mengalami memar adalah pinggul, pantat, sendi kaki dan tumit. Bila memar ini tidak pengaruh dirawat dengan baik maka akan terjadi ulkus dekubitus dan infeksi.

3. Pneumonia Pasien stroke tidak bisa batuk dan menelan dengan sempurna, hal ini menyebabkan cairan terkumpul di paruparu dan selanjutnya menimbulkan pneumoni.

\subsubsection{Manifestasi Klinis}

Menurut (Nurarif Huda, 2016), manifestasi klinis stroke sebagai berikut:

1. Tiba-tiba mengalami kelemahan atau kelumpuhan separuh badan

2. Tiba-tiba hilang rasa peka

3. Bicara pelo

4. Gangguan bicara dan bahasa

5. Gangguan penglihatan

6. Mulut mencong atau tidak simetris ketika menyeringai

7. Gangguan daya ingat

8. Nyeri kepala hebat

9. Vertigo

10. Kesadaran menurun

11. Proses kencing terganggu

12. Gangguan fungsi otak 


\subsubsection{Klasifikasi}

1. Stroke iskemik transien (Transtien ischemic attack/TIA) Stroke ini biasa disebut dengan stroke kecil, dimana stroke yang terjadi pada periode singkat iskemik serebral terlokalisasi yang menyebabkan defisit neurologis yang berlangsung selama kurang dari 2324 jam. TIA disebabkan karena gangguan inflamasi arteri, anemia sel sabit, perubahan aterosklerosis pada arteri karotis dan serebral, trombosis, serta emboli. Manifestasi neurologis TIA beragam berdasarkan lokasi dan ukuran pembuluh serebral yang terkena dan memiliki awitan tiba-tiba. Biasanya terjadi defisit meliputi kebas kontralateral atau kelemahan tungkai, tangan, lengan bawah dan pusat mulut, afasia dan gangguan penglihatan buram serta fugaks amaurosis (kebutaan yang cepat pada satu mata).

2. Stroke pembuluh darah besar (trombolisis) Stroke trombotik adalah tipe stroke yang paling umum, dimana sering dikaitkan dengan aterosklerosis dan menyebabkan penyempitan lumen arteri, sehingga menyebabkan gangguan masuknya darah yang menuju ke bagian otak.

3. Reversible Ischemic Neurological Deficit (RIND) Tanda dan gejala gangguan persarafan yang berlangsung dalam waktu yang lama lama. Kondisi RIND dan TIA mempunyai kesamaan, hanya saja RIND berlangsung maksimal 1 minggu (7 hari) dan kemudian pulih kembali (dalam jangka waktu 3 minggu) serta tidak meninggalkan gejala sisa (Masriadi, 2016)

\subsubsection{Pemeriksaan penunjang}

Pemeriksaan penunjang yang dilakukan pada pasiendengan stroke non hemoragik adalah sebagai berikut (Radaningtyas, 2018)

a. Angiografi serebral Membantu menentukan penyebab stroke secara spesifik seprti perdarahan, obstruktif arteri, oklusi / nuptur. 25

b. Elektro encefalography Mengidentifikasi masalah didasrkan pada gelombang otak atau mungkin memperlihatkan daerah lesi yang spesifik.

c. Sinar x tengkorak Menggambarkan perubahan kelenjar lempeng pineal daerah yang berlawan dari masa yang luas, klasifikasi karotis interna terdapat pada trobus serebral. Klasifikasi persial dinding, aneurisma pada pendarahan sub arachnoid. 
d. Ultrasonography Doppler Mengidentifikasi penyakit arteriovena (masalah system arteri karotis /alioran darah /muncul plaque / arterosklerosis.

e. CT-Scan Memperlihatkan adanya edema, hematoma, iskemia, dan adanya infark.

f. Magnetic Resonance Imagine (MRI) Menunjukan adanya tekanan anormal dan biasanya ada thrombosis, emboli, dan TIA, tekanan meningkat dan cairan mengandung darah menunjukan, hemoragi sub arachnois / perdarahan intakranial.

g. Pemeriksaan foto thorax Dapat memperlihatkan keadaan jantung, apakah terdapat pembesaran vertrikel kiri yang merupakan salah satu tanda hipertensi kronis pada penderita stroke, menggambarkn perubahan kelenjar lempeng pineal daerah berlawanan dari massa yang meluas.

\subsubsection{Penatalaksanaan}

Menurut penelitian (Setyopranoto, 2016) penatalaksanaan pada pasien stroke non hemoragik adalah sebagai berikut:

a. Pentalaksanaan umum

1) Pada fase akut

a) letakkan kepala pasien pada posisi $30^{\circ}$, kepala dan dada pada satu bidang; ubah posisi tidur setiap 2 jam; mobilisasi dimulai bertahap bila hemodinamik sudah stabil.

b) Bebaskan jalan nafas, beri oksigen 1-2 liter/menit sampai didapatkan hasil analisa gas darah. Jika perlu, dilakukan intubasi.

c) Demam diatasi dengan kompres dan antipiretik, kemudian dicari penyebabnya; jika kandung kemih penuh, dikosongkan (sebaiknya dengan kateter intermiten)

d) Pemberian nutrisi dengan cairan isotonik, stroke berisiko terjadinya dehidrasi karena penurunan kesadaran atau mengalami disfagia. Terapi cairan ini penting untuk mempertahankan sirkulasi darah dan tekanan darah. kristaloid atau koloid 1500$2000 \mathrm{ml}$ dan elektrolit sesuai kebutuhan, hindari cairan mengandung glukosa atau salin isotonik. Pemberian nutrisi melalui oral hanya dilakukan jika fungsi menelan baik, dianjurkan menggunakan nasogastriktube. 
e) Pantau juga kadar gula darah $>150 \mathrm{mg} \%$ harus dikoreksi sampai batas gula darah sewaktu $150 \mathrm{mg} \%$ dengan insulin drip intravena kontinu selama 2-3 hari pertama.

f) Tekanan darah tidak perlu segera diturunkan, kecuali bila tekanan sistol >220 mmHg, diastol >120 mmHg, Mean Arteri Blood Plessure (MAP) >130 mmHg (pada 2 kali pengukuran dengan selang waktu 30 menit), atau didapatkan infark miokard akut, gagal jantung kongestif serta gagal ginjal.

g) Penurunan tekanan darah maksimal adalah $20 \%$ dan obat yang direkomendasikan yaitu natrium nitropusid, penyekat reseptor alfabeta, penyekat ACE, atau antagonis kalsium.

\subsection{Konsep Ketidakberdayaan}

\subsubsection{Definisi Ketidakberdayaan}

Ketidakberdayaan adalah pengalaman hidup kurang pengendalian terhadap situasi, termasuk persepsi bahwa tindakan seseorang secara signifikan tidak akan mempengaruhi hasil (NANDA-1, 2018). Ketidakberdayaan adalah persepsi seseorang bahwa tindakannya tidak akan mempengaruhi hasil secara bermakna; suatu keadaan ketika individu kurang mengendalik'an kondisi tertentu atau kegiatan yang baru dirasakan (Stuart,2016)

Ketidakberdayaan juga dapat diartikan sebagai sebuah persepsi individu bahwa tindakannya sendiri tidak akan mempengaruhi hasil secara bermakna; kurangnya control terhadap situasi tertentu (Townsend,2017). Dari beberapa definisi yang telah dijelaskan dapat disimpulkan bahwa ketidakberdayaan adalah suatu kondisi dimana control akan pribadi dan situasi, termasuk persepsi oraang atau kelompok mengenai tindakan yang dilakukan tidak akan mempengaruhi hasil yang signifikan. Ketidakberdayaan dapat dialami oleh semua orang tanpa terkecuali, pada klien dengan masalah kesehatan yang sedang menjalani pengobatan dan perawatan di rumah sakit. Seperti pada klien dengan diabetes miletus yang sedang menjalani perawatan. Kannie, Dauli, Nuraini (2018) 
Menjelaskan bahwa kondisi stress pada klien dapat menyertai perasaan ketidakberdayaan. Stress yang dialami oleh klien dapat memberikan dampak pula pada ketidakberdayaan klien. Kondisi tersebut dapat memperparah kondisi klien. Pada klien mengalami ketidakberdayaan, penting untuk memberikan intervensi keperawatan tentang persepsi klien terhadap penyakit diabetes miletus supaya dapat berubah menjadi persepsi yanag baik dan menjadi pandangan positif tentang usaha penyembuhan penyakitnya

\subsubsection{Etiologi ketidakberdayaan}

Menurut buku asuhan keperawatan jiwa (Keliat,Budi Anna. 2019)

1. Nyeri

2. Ansietas

3. Hargadiri rendah

4. Strategi koping tidak efektif

5. Kurang pengetahuan untuk mengelola masalah

6. Kurang dukungan social

\subsubsection{Faktor Presdiposisi dan Faktor Prespitasi}

1. Faktor predisposes

2. Biologis :

a. Tidak ada riwayat keturunan (salah satu atau kedua orang tua menderita gangguan jiwa)

b. Gaya hidup (tidak merokok, alkhohol, obat dan zat adiktif) dan Pengalaman penggunaan zat terlarang

c. Menderita penyakit kronis (riwayat melakukan general chek up, tanggal terakhir periksa)

d. Ada riwayat menderita penjakit jantung, paru-paru, yang mengganggu pelaksana aktivitas harian pasien Adanya riwayat sakit panas lama saat perkembangan balita sampai kejang-kejang atau pernah mengalami riwayat trauma kepala yang menimbulkan lesi pada lobus frontal, temporal dan limbic. 
e. Riwayat menderita penyakit yang secara progresif menimbulkan ketidakmampuan, misalnya: sklerosis multipel, kanker terminal atau AIDS

3. Psikologis :

a. Pengalaman perubahan gaya hidup akibat lingkungan tempat tinggal

b. Ketidaknmampuan mengambil keputusan dan mempunyai kemampuan komunikasi verbal yang kurang atau kurang dapat mengekspresikan perasaan terkait dengan penyakitnya atau kondisi dirinya

c. Ketidakmampuan menjalankan peran akibat penyakit yang secara rogresif menimbulkan ketidakmampuan, misalnya: sklerosis multipel, kanker terminal atau AIDS

d. Kurang puas dengan kehidupannya (tujuan hidup yang sudah dicapai)

e. Merasa frustasi dengan kondisi kesehatannya dan kehidupannya yang Sekarang

1. Pola asuh orang tua pada saat klien anak hingga remaja yang terlalu otoriter atau terlalu melindungi/menyayangi

2. Motivasi: penerimaan umpan balik negatif yang konsisten selama tahap

3. perkembangan balita hingga remaja, kurang minat dalam

4. mengembangkan hobi dan aktivitas sehari-hari

5. Pengalaman aniaya fisik, baik sebagai pelaku, korban maupun sebagai

6. saksi

7. Self kontrol: tidak mampu mengontrol perasaan dan emosi, mudah

8. cemas, rasa takut akan tidak diakui, gaya hidup tidak berdaya

9. Kepribadian: mudah marah, pasif dan cenderung tertutup.

4. Sosial budaya :

a. Usia 30-meninggal berpotensi mengalami ketidakberdayaan

b. Jenis kelamin laki-laki ataupun perempuan mempunyai kecenderungan

c. yang sama untuk mengalami ketidakberdayaan tergantung dari peran

d. yang dijalankan dalam kehidupannya 
e. Pendidikan rendah

f. Kehilangan kemampuan melakukan aktivitas akibat proses penuaan (misalnya: pensiun, defisit memori, defisit motorik, status finansial atau

g. orang terdekat yang berlangsung lebih dari 6 bulan)

h. Adanya norma individu atau masyarakat yang menghargai kontrol

i. (misalnya kontrol lokus internal)

1. Dalam kehidupan sosial, cenderung ketergantungan dengan orang lain,

2. tidak mampu berpartisipasi dalam sosial kemasyarakatan secara aktif,

3. enggan bergaul dan kadang menghindar dari orang lain

4. Pengalaman sosial, kurang aktif dalam kegiatan di masyarakat

5. Kurang terlibat dalam kegiatan politik baik secara aktif maupun secara

6. pasif.

\subsubsection{Faktor Presipitasi}

Faktor presipitasi dapat menstimulasi klien jatuh pada kondisi ketidakberdyaan dipengaruhi oleh kondisi internal dan eksternal. Kondisi internal dimana pasien kurang dapat menerima perubahan fisik dan psikologis yang terjadi. Kondisi eksternal biasanya keluarga dan masyarakat kurang mendukung atau mengakui keberadaannya yang sekarang terkait dengan perubahan fisik dan perannya. Sedangkan durasi stressor terjadi kurang lebih 6 bulan terakhir, dan waktu terjadinya dapat bersamaan, silih berganti atau hampir bersamaan, dengan jumlah stressor lebih dari satu dan mempunyai kualitas yang berat. Hal tersebut dapat menstimulasi ketidakberdayaan bahkan memperberat kondisi ketidakberdayaan yang dialami oleh klien. Faktor-faktor lain yang berhubungan dengan faktor presiptasi timbulnya ketidakberdayaan adalah sebagai berikut :

a. Biologis :

1. Menderita suatu penyakit dan harus dilakukan terapi tertentu, Program pengobatan yang terkait dengan penyakitnya (misalnya jangka panjang, sulit dan kompeks) (proses intoksifikasi dan rehabilitasi).

2. Kambuh dari penyakit kronis dalam 6 bulan terakhir 
3. Dalam enam bulan terakhir mengalami infeksi otak yang menimbulkan

4. kejang atau trauma kepala yang menimbulkan lesi pada lobus frontal,

5. temporal dan limbic

I. Terdapat gangguan sistem endokrin

II. Penggunaan alkhohol, obat-obatan, kafein, dan tembakau

III. Mengalami gangguan tidur atau istirahat

IV. Kurang mampu menyesuaikan diri terhadap budaya, ras, etnik dan

6. gender

b. Psikologis :

1. Perubahan gaya hidup akibat menderita penyakit kronis

2. Tidak dapat menjalankan pekerjaan, hobi, kesenangan dan aktivitas

3. sosial yang berdampak pada keputusasaan.

4. Perasaan malu dan rendah diri karena ketidakmampuan melakukan

5. aktivitas kehidupan sehari-hari akibat tremor, nyeri, kehilangan

6. pekerjaan.

a. Konsep diri: gangguan pelaksanaan peran karena ketidakmampuan melakukan tanggungjawab peran.

b. Kehilangan kemandirian atau perasaan ketergantungan dengan orang lain.

c. Sosial budaya :

1. Kehilangan pekerjaan dan penghasilan akibat kondisi kesehatan atau

2. kehidupannya yang sekarang.

3. Tinggal di pelayanan kesehatan dan pisah dengan keluarga (berada

4. dalam lingkungan perawatan kesehatan).

5. Hambatan interaksi interpersonal akibat penyakitnya maupun penyebab

6. yang lain Kehilangan kemampuan melakukan aktivitas akibat proses penuaan (misalnya: pensiun, defisit memori, defisit motorik, status finansial atau

7. orang terdekat yang berlangsung dalam 6 bulan terakhir)

a. Adanya perubahan dari status kuratif menjadi status paliatif.

b. Kurang dapat menjalankan kegiatan agama dan keyakinannya dan

8. ketidakmampuan berpartisipasi dalam kegiatan sosial di masyarakat

a. Harapan

b. Respon adaftif

c. Respon Maladaftif 
d. Harapan

e. Kesempatan

f. Ketidakpastian

g. Bahaya

h. Tidak Berdaya

Putus Asa Harapan akan mempngaruhi respons psikologis terhadap penyakit fisik. Kurangnya harapan dapat meningkatkan stres dan berakhir dengan penggunaan mekanisme koping yang tidak adekuat. Pada beberapa kasus, koping yang tidak adekuat dapat menimbulkan masalah kesehatan jiwa.

9. Ketidak pastian

Ketidakpastian adalah suatu keadaan dimana individu tidak mampu kejadian yang terjadi. Hal ini akan mempengaruhi kemmapuan individu mengkaji situasi dan memperkirakan upaya yang akan dilakukan. Ketidakpastian menjadi berbahaya jika disertai rasa pesimis dan putus asa.

10. Putus asa

Putus asa ditandai dengan perilaku pasif, perasaan sedih dan harapan hampa, kondisi ini dapat membawa klien dalam upaya bunuh diri.

\subsubsection{Sumber Koping}

1. Personal ability

a. Pengetahuan klien tentang masalah yang dirasakan (ketidakberdayaan).

b. Kemampuan klien mengatasi masalah yang dirasakan (ketidakberdayaan).

c. Jenis upaya klien mengatasi masalah yang dirasakan (ketidakberdayaan).

d. Kemampuan dalam memecahkan masalah.

2. Sosial support

a. Caregiver utama dalam keluarga.

b. Kader kesehatan yang ada di lingkungan tempat tinggal.

c. Peer group yang ada turut serta dalam memberi dukungan.

d. Material asset1) Keberadaan asset harta benda pendukung pengobatan yang dimiliki (tanah, 
e. rumah, tabungan) serta fasilitas yang membantunya selama proses gangguan fisiologis.

f. Mempunyai fasilitas Jamkesmas, SKTM, ASKES.

g. Arak/ akses pelayanan kesehatan yang dikunjungi

3. Positive belief

a. Keyakinan dan nilai positif tentang ketidakberdayaan yang dirasakan: tidak ada.

b. Keyakinan dan nilai positif tentang pelayanan kesehatan yang ada.

\subsubsection{Mekanisme Koping}

1. Konstruktif

a. Menilai pencapaian hidup yang realistis.

b. Kreatif dalam mencari informasi terkait perubahan status kesehatannya sehingga dapat beradaptasi secara normal.

c. Mampu mengembangkan minat dan hobi baru sesuai dengan perubahan status kesehatan dan peran yang telah dialami.

d. Peduli terhadap orang lain disekitarnya walaupun mengalami perubahan kondisi kesehatan.

2. Destruktif

a. Mengungkapkan ketidakmampuan untuk mengatasi masalah atau meminta

b. bantuan.

c. Menggunakan mekanisme pertahanan yang tidak sesuai.

d. Ketidakmampuan memenuhi peran yang diharapkan (mengalami ketegangan

e. peran, konflik peran).

f. Mengungkapkan kesulitan dalam berkeinginan mencapai tujuan.

g. Tidak mampu memenuhi kebutuhan dasar seperti makan minum, kebersihan diri,

h. istirahat dan tidur dan berdandan

i. Perubahan dalam interaksi sosial (menarik diri, bergantung pada orang lain).

j. Enggan mengungkapkan perasaan yang sebenarnya. 


\subsubsection{Gejala Ketidak berdayaan Mayor}

1. Subjektif

a. Mengatakan ketidakmampuan

b. Frustasi karena tidak mampu mengatasi situasi

2. Objektif
a. Tidak mampu merawat diri
b. Tidak mampu mencari informasi perawatan
c. Tidak mampu memutuskan
d. Bergantung pada orang lain

3. Minor
a. Subjektif
iii. malu
b. Objektif
i. Kurang partispasi dalam perawatan
ii. Depresi

i. Menyatakan keraguan tentang kemempuannya

ii. Menyatakan kurang mampu mengontrol situasi

\subsubsection{Diagnosa Keperawatan}

1. ketidakberdayaan

2. kecemasan

3. Koping individu tidak efektif

\subsubsection{Tujuan Asuhan Keperawatan}

1. Kognitif ,klien mampu
a. Menegtahui pengertian, tanda dan gejala, penyebab dan akibat dari ketidakberdayaan
b. Mengetahui cara mengatasi ketidakberdayaan

2. Psikomotor, klien mampu
a. Mengidentifikasi situasi hidup yang tidak dapat dikendalikan dan dapat dikendalikan
b. Melatih situasi hidup yang dapat dikendalikan
c. Mengidentifikasi pikiran negative yang tidak sesuai 
d. Melatih pikiran positif, pikiran rasional, dan harapan positif

3. Afektif ,klien mampu

a. Merasakan manfaat latihan yang dilakukan

b. Menilai latihan yang mengatasi ketidakberdayaan 


\section{TINJAUAN KASUS}

\subsubsection{PENGKAJIAN KEPERAWATAN}

\begin{tabular}{|l|l|}
\hline Nama : Tn S & $\begin{array}{l}\text { Kondisi saat MRS: kondisi sangat lemah dan memerlukan } \\
\text { Usia : } 48 \text { tahun } \\
\text { Tahun no reg : - } \\
\text { Ruangan : - }\end{array}$ \\
Tgl masuk rs: - & $\begin{array}{l}\text { Kondisi saat ini : lemah dan tidak berdaya hanya bisa } \\
\text { terutama wajah dan kaki } \\
\text { Tgl pengkajian : } 7 \text { November } 2021\end{array}$ \\
Alamat : Simalingkar Kec Medan Tuntungan & \\
\end{tabular}




\subsubsection{FAKTOR PREDISPOSISI DAN FAKTOR PRESIPITASI}

\begin{tabular}{|c|c|c|c|c|}
\hline \multirow[t]{2}{*}{ Faktor predisposisi } & \multicolumn{3}{|l|}{ Faktor presipitasi } & \multirow[t]{2}{*}{ STRESSOR } \\
\hline & Nature & Origin & $\begin{array}{l}\text { Number \& } \\
\text { Timing }\end{array}$ & \\
\hline 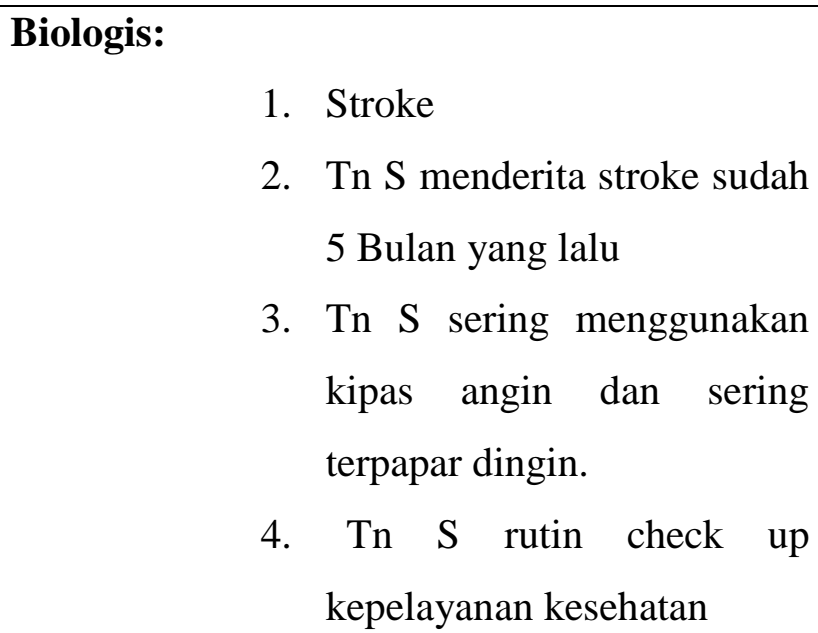 & - Kondisi & Internal & $\begin{array}{l}\text { Sejak } 5 \text { bulan } \\
\text { yang lalu }\end{array}$ & - Stroke \\
\hline $\begin{array}{l}\text { Psikologis : } \\
\begin{array}{l}\text { 1. Tn } \mathrm{S} \text { memiliki kepribadian yang tertutup } \\
\text { dan tidak mau bertemu orang banyak. } \\
\text { 2. Tn } \mathrm{S} \text { merasa tidak bisa menggerakan } \\
\text { sebelah wajahnya,kesulitan makan. }\end{array}\end{array}$ & $\begin{array}{l}\text { - Takut, gelisah, } \\
\text { dan putus asa } \\
\text { bagaimana jika } \\
\text { penyakit ini tidak } \\
\text { sembuh. } \\
\text { - Sering kepikiran } \\
\text { penyakitnya. }\end{array}$ & Internal & $\begin{array}{l}\text { Sejak } 1 \text { Bulan } \\
\text { yang lalu }\end{array}$ & $\begin{array}{l}\text { - Cemas, takut, panik, khawatir, } \\
\text { gelisah }\end{array}$ \\
\hline Sosiocultural : & $\bullet$ & & & $\bullet$ \\
\hline
\end{tabular}




\begin{tabular}{|l|l|l|l|}
\hline 1. Tn S seorang Laki laki umur 48 tahun & & & \\
2. Tn S sudah menikah & & & \\
3. Tn S merupakan Sorang petani \\
4. Sebelumnya Tn. S Aktif dalam bekerja \\
setiap hari \\
5. Tn $\mathrm{S}$ merupakan orang jawa dan \\
menurut tidak ada kebiasaan yang \\
bertentangan dengan kesehatan. \\
6. $\begin{array}{l}\text { Tn beragama islam dan taat } \\
\text { menjalankan ibadah } \\
\text { 7n S Rutin check up penyakitnya. }\end{array}$
\end{tabular}




\subsubsection{PENILAIAN (RESPON)TERHADAP STRESSOR}

\begin{tabular}{|c|c|c|c|c|c|c|}
\hline STRESSOR & KOGNITIF & AFEKTIF & FISIOLOGIS & PERILAKU & SOSIAL & $\begin{array}{l}\text { DIAGNOSA } \\
\text { KEPERAWATAN }\end{array}$ \\
\hline $\begin{array}{l}\text { BIOLOGIS } \\
\text { - Stroke }\end{array}$ & $\begin{array}{l}\text { - Menurut Tn S } \\
\text { dia menderita } \\
\text { penyakit ini } \\
\text { dikarenakan } \\
\text { Pernah } \\
\text { terjatuh } \\
\text { dikamar mandi } \\
\text { dan juga } \\
\text { disebabkan } \\
\text { stress } \\
\text { berlebihan } \\
\text { akibat } \\
\text { pekerjaan. } \\
\text { - Menganggap } \\
\text { penyakit } \\
\text { yang diderita } \\
\text { tidak akan } \\
\text { bias sembuh } \\
\text { - Tidak tahu apa } \\
\text { yang harus } \\
\text { dilakukan } \\
\text { untuk } \\
\text { penyakitnya } \\
\text { karena sudah } \\
\text { berapa kali } \\
\text { terapi tidak } \\
\text { kunjung } \\
\text { sembuh. } \\
\text { - Dan tidak bisa }\end{array}$ & $\begin{array}{l}\text { - Tn S merasa } \\
\text { sedih dan } \\
\text { bingung } \\
\text { dengan } \\
\text { kondisi } \\
\text { penyakitnya } \\
\text { dan kerap } \\
\text { Termenung } \\
\text { Dan juga } \\
\text { putus asa }\end{array}$ & $\begin{array}{l}\text { - Sulit tidur } \\
\text { - Tidak nafsu } \\
\text { makan } \\
\text { - Tn. S tampak } \\
\text { lemas } \\
\text { - Pemeriksaan } \\
\text { TTV } \\
\text { TD: } 140 / 90 \\
\text { Mmhg }\end{array}$ & $\begin{array}{l}\text { - Tn S rutin } \\
\text { ke rumah } \\
\text { sakit } \\
\text { - Ekspresi } \\
\text { muka lesu } \\
\text {,lemas } \\
\text { Tn S tampak } \\
\text { diam dan } \\
\text { Hanya duduk } \\
\text { dan } \\
\text { termenung } \\
\text { sepanjang } \\
\text { hari. }\end{array}$ & $\begin{array}{l}\text { - Pasien } \\
\text { mendatangi dan } \\
\text { menggunaka n } \\
\text { fasilitas } \\
\text { kesehatan yang } \\
\text { ada untuk } \\
\text { mencari } \\
\text { kesembuhan } \\
\text { terhadap } \\
\text { masalah yang } \\
\text { dihadapi saat } \\
\text { ini. }\end{array}$ & - Ketidakberdayaan \\
\hline
\end{tabular}




\begin{tabular}{|c|c|c|c|c|c|c|}
\hline & $\begin{array}{l}\text { melakukan } \\
\text { apapun } \\
\text { termaksud } \\
\text { pekerjaan } \\
\text { yang sekrnag } \\
\text { jadi sumber } \\
\text { penghidupan. }\end{array}$ & & & & & \\
\hline $\begin{array}{l}\text { PSIKOLOGIS } \\
\text { - sedih, cemas, } \\
\text { kesal dan } \\
\text { Bingung } \\
\text { dengan kondisi } \\
\text { penyakit dan } \\
\text { Penyemb } \\
\text { uhannya } \\
\text { yang } \\
\text { begitu } \\
\text { lama, } \\
\text { serta }\end{array}$ & $\begin{array}{l}\text { - Tn S tahu } \\
\text { bahwa } \\
\text { Wajahnya } \\
\text { menurun dan } \\
\text { tidak bias di } \\
\text { gerakan } \\
\text { - Tn S mengaku } \\
\text { Sangat sedih } \\
\text { dan tidak } \\
\text { ingin bertemu } \\
\text { dengan } \\
\text { siapapun dan } \\
\text { sangat malu } \\
\text { ketka bertemu }\end{array}$ & $\begin{array}{l}\text { - Merasa kesal } \\
\text { dan putus asa } \\
\text { dengan } \\
\text { penyakitnya } \\
\text { yang tidak } \\
\text { sembuh- } \\
\text { sembuh } \\
\text { padahal sudah } \\
\text { beberapa } \\
\text { bulan. }\end{array}$ & $\begin{array}{l}\text { - } \text { Pusing } \\
\text { - Nyeri sedang } \\
\text { - Sulit tidur dan } \\
\text { sering } \\
\text { terbangun } \\
\text { apabila tidur } \\
\text { - Kepala dan } \\
\text { belakang } \\
\text { telinga terasa } \\
\text { sakit. } \\
\text { - Tidak nafsu } \\
\text { makan } \\
\text { - Tn S tampak } \\
\text { lemas }\end{array}$ & $\begin{array}{l}\text { - } \text { Tampak } \\
\text { cemas dan } \\
\text { tidak } \\
\text { tenang } \\
\text { - } \text { Kadang Tn } \\
\text { S tampak } \\
\text { murung } \\
\text { - Tn S } \\
\text { tampak } \\
\text { gelisah } \\
\text { - Tn S } \\
\text { tampak } \\
\text { aktif dalam } \\
\text { menerima }\end{array}$ & $\begin{array}{l}\text { - Hubungan Tn } \\
\text { S dengan } \\
\text { keluarga baik } \\
\text { - Tn S kurang } \\
\text { bersosialisasi } \\
\text { dengan } \\
\text { keluarga } \\
\text { Tn S tetap } \\
\text { mengikuti } \\
\text { program } \\
\text { pengobatan } \\
\text { yang } \\
\text { diberikan } \\
\text { kepadanya }\end{array}$ & - Ansietas \\
\hline
\end{tabular}




\begin{tabular}{|c|c|c|c|c|c|c|}
\hline Perawatannya & $\begin{array}{l}\text { dengan orang } \\
\text { banyak. }\end{array}$ & & $\begin{array}{l}\text { - Kaki dan } \\
\text { wajah Tn S } \\
\text { tampak tidak } \\
\text { simetris dan } \\
\text { turun dan kaki } \\
\text { tidak bisa } \\
\text { digerakan. } \\
\text { - Wajah Tn S } \\
\text { tampak pucat. } \\
\text { - Pemeriksaan } \\
\text { TTV } \\
\text { TD: } 140 / 90 \\
\text { mmhg } \\
\mathrm{N}: 88 \times / \text { menit } \\
\mathrm{P}: 20 \times / \text { menit } \\
\text { S: } 360 \mathrm{C}\end{array}$ & $\begin{array}{lr}\text { perawatan } & \\
\text { Tn. } & \text { S } \\
\text { menunduk saat } \\
\text { bercerita } & \text { dan } \\
\text { jarang } & \text { ada } \\
\text { kontak mata. }\end{array}$ & $\begin{array}{l}\text { akan tetapi } \\
\text { tidak begitu } \\
\text { antusias dan } \\
\text { Tn S dalam } \\
\text { menerima } \\
\text { perawatan }\end{array}$ & - Kecemasan \\
\hline $\begin{array}{l}\text { sering } \\
\text { Memikirkan } \\
\text { Apakah } \\
\text { penyakitnya } \\
\text { bisa sembuh } \\
\text { dan sangat } \\
\text { sedih karena } \\
\text { setiap jumpa } \\
\text { keluarga pasti } \\
\text { bertanya } \\
\text { kenapa bisa } \\
\text { terserang } \\
\text { penyakit itu } \\
\text { dan membuat } \\
\text { sangat malu }\end{array}$ & $\begin{array}{l}\text { - Tn S merasa } \\
\text { tidak berdaya } \\
\text { dengan } \\
\text { keadaannya } \\
\text { sejarang yang } \\
\text { tidak bias } \\
\text { mengunyah } \\
\text { dengan baik } \\
\text { begitu juga } \\
\text { ketika akan } \\
\text { tersenyum dan } \\
\text { berbicara. } \\
\text { - Tn S berfikir } \\
\text { ia selalu } \\
\text { merepotkan } \\
\text { kluarga }\end{array}$ & $\begin{array}{l}\text { - Merasa } \\
\text { khawatir dan } \\
\text { sedih kepada } \\
\text { dirinya } \\
\text { sendiri. } \\
\text { - Merasa } \\
\text { bersalah } \\
\text { karena } \\
\text { merasa } \\
\text { merepotkan } \\
\text { keluarga } \\
\text { - Merasa } \\
\text { bosan } \\
\text { dengan } \\
\text { keadaan } \\
\text { sekarang }\end{array}$ & $\begin{array}{l}\text { - } \text { Pusing } \\
\text { - bibir tampak } \\
\text { kering } \\
\text { - mata cekung } \\
\text { - Sulit tidur } \\
\text { - kepala terasa } \\
\text { tegang } \\
\text { - Tidak nafsu } \\
\text { makan } \\
\text { - Tn S tampak } \\
\text { lemas } \\
\text { - Wajah Tn S } \\
\text { tampak pucat } \\
\text { Seperti } \\
\text { kekurangan }\end{array}$ & $\begin{array}{l}\text { - Kontak mata } \\
\text { ada tapi tidak } \\
\text { bertahan } \\
\text { lama dan } \\
\text { sering } \\
\text { menunduk } \\
\text { - Volume } \\
\text { suara } \\
\text { mengecil } \\
\text { - Tn S tampak } \\
\text { gelisah Dan } \\
\text { khawatir. }\end{array}$ & $\begin{array}{l}\text { - Hubungan Tn } \\
\mathrm{S} \text { dengan } \\
\text { keluarga baik } \\
\text { - Hubungan Tn } \\
\mathrm{S} \text { dengan } \\
\text { petugas } \\
\text { kesehatan } \\
\text { baik } \\
\text { - Tn S tetap } \\
\text { mengikuti } \\
\text { program } \\
\text { pengobatan } \\
\text { Dan terus } \\
\text { menjalani } \\
\text { terapi. }\end{array}$ & - Keputusasaan \\
\hline
\end{tabular}




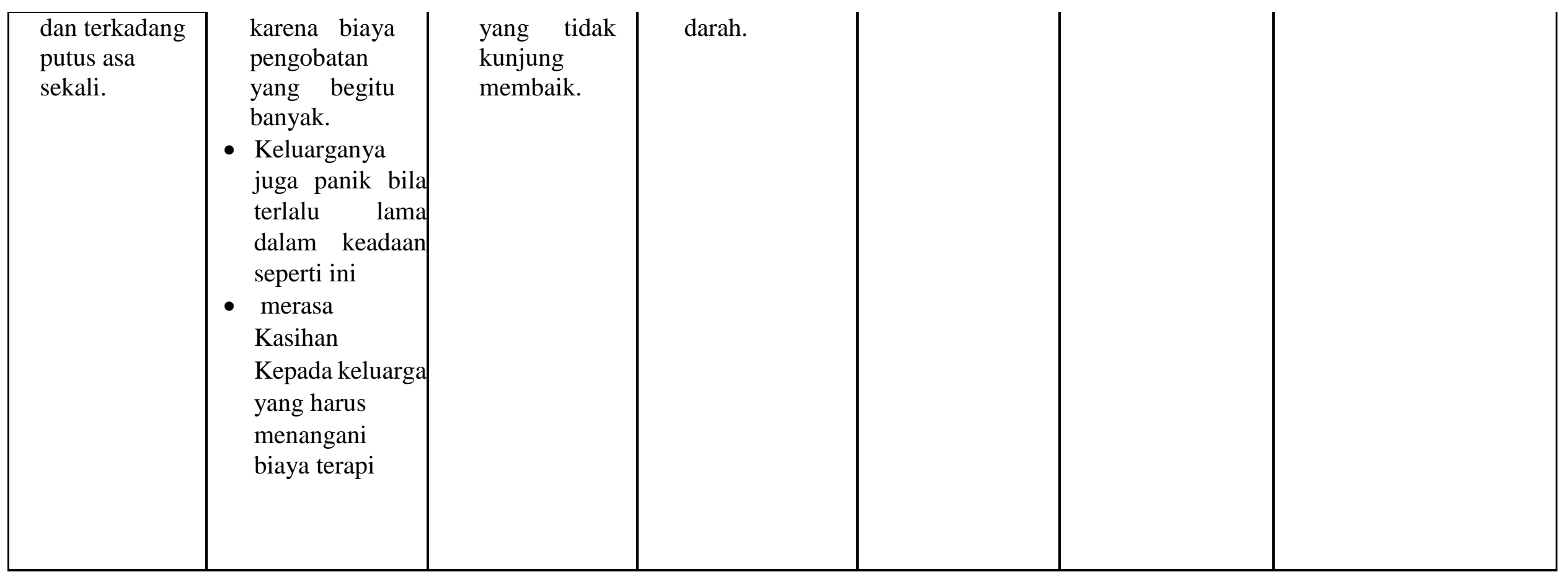




\subsubsection{SUMBER KOPING}

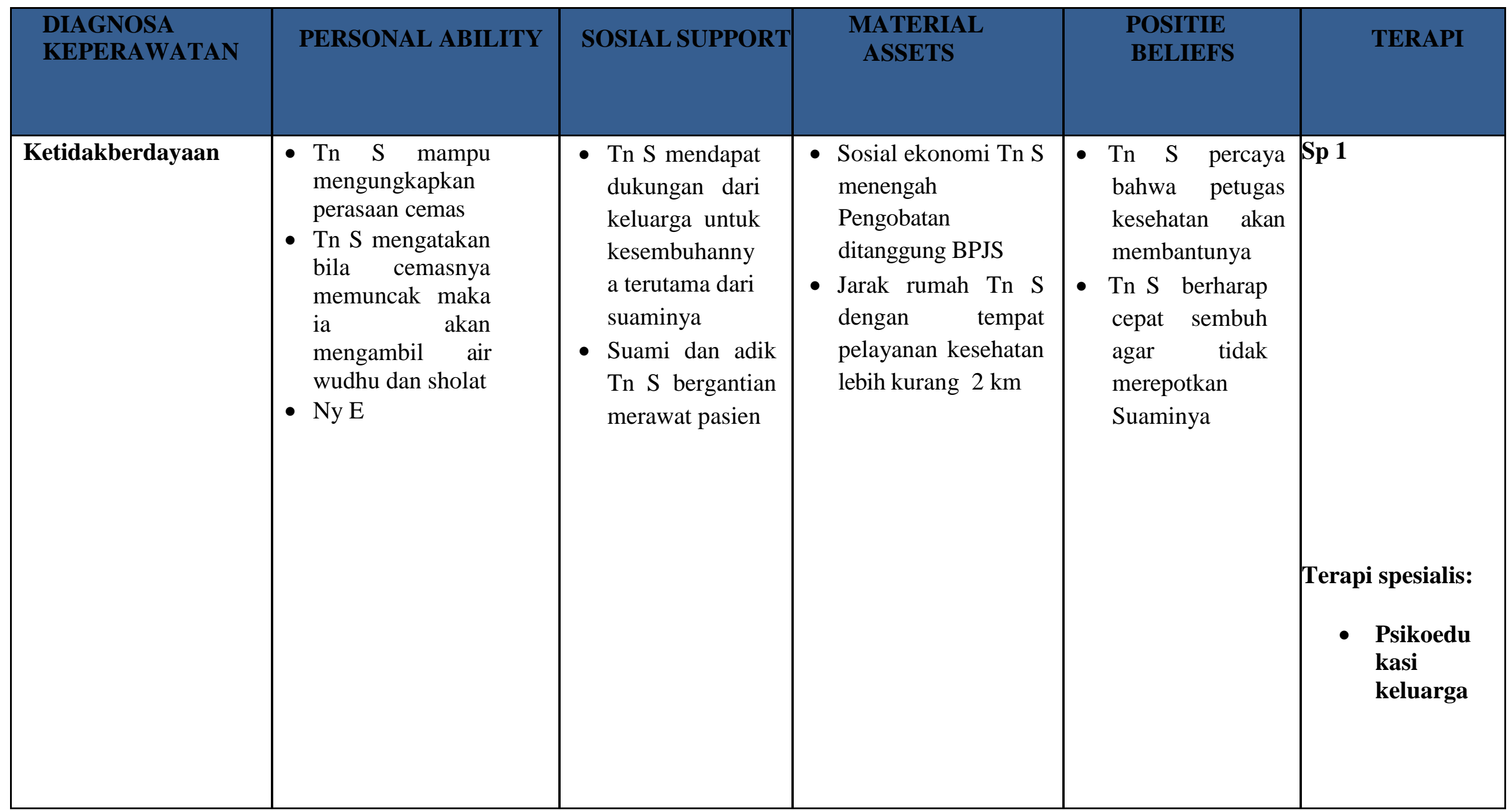




\begin{tabular}{|c|c|c|c|}
\hline Ansietas & $\begin{array}{l}\text { - Ny. E Mengatakan } \\
\text { wajahnya sangat } \\
\text { tidak enak di } \\
\text { lihatdan dia bias } \\
\text { memberitahukan } \\
\text { dengan jelas bagian } \\
\text { tubuh atau wajah } \\
\text { mana yang } \\
\text { bermasalah. } \\
\text { - Ny. } \\
\text { mengatakan } \\
\text { bahwasannya } \\
\text { keluarga juga } \\
\text { mengeluh soal } \\
\text { penyakit nya ini. }\end{array}$ & $\begin{array}{l}\text { - Ny.E selalu } \\
\text { berdoa untuk } \\
\text { kesembuhan } \\
\text { penyakitnya } \\
\text { - Ny.E Kadang } \\
\text { yakin, bila ia } \\
\text { mengikuti } \\
\text { petunjuk dan } \\
\text { saran dari } \\
\text { petugas } \\
\text { kesehatan maka } \\
\text { ia akan cepat } \\
\text { sembuh tetapi } \\
\text { terkadang ia juga } \\
\text { ragu } \\
\text { bahwasannya } \\
\text { penyakitnya } \\
\text { tidak akan } \\
\text { sembuh } \\
\text { - Ny.E percaya } \\
\text { bahwa petugas } \\
\text { kesehatan akan } \\
\text { membantunya } \\
\text { Ny.E berharap } \\
\text { cepat sembuh } \\
\text { agar tidak } \\
\text { merepotkan } \\
\text { Keluarganya. }\end{array}$ & $\begin{array}{l}\text { SP 1 } \\
\text { SP 2 }\end{array}$ \\
\hline
\end{tabular}




\begin{tabular}{|c|c|c|c|c|}
\hline Keputusasaan & $\begin{array}{l}\text { - Tn S Tidak mampu } \\
\text { mengenal dan menilai } \\
\text { Komplikasi dari } \\
\text { penyakitnya. } \\
\text { - Tn S tidak mampu } \\
\text { melatih cara hidup } \\
\text { sehat. }\end{array}$ & $\begin{array}{l}\text { - Tn S Tidak } \\
\text { mendapat } \\
\text { dukungan dari } \\
\text { keluarga untuk } \\
\text { kesembuhannya } \\
\text { - Ayah dan ibu Tn } \\
\text { S bergantian } \\
\text { mengantarpasien } \\
\text { terapi. }\end{array}$ & 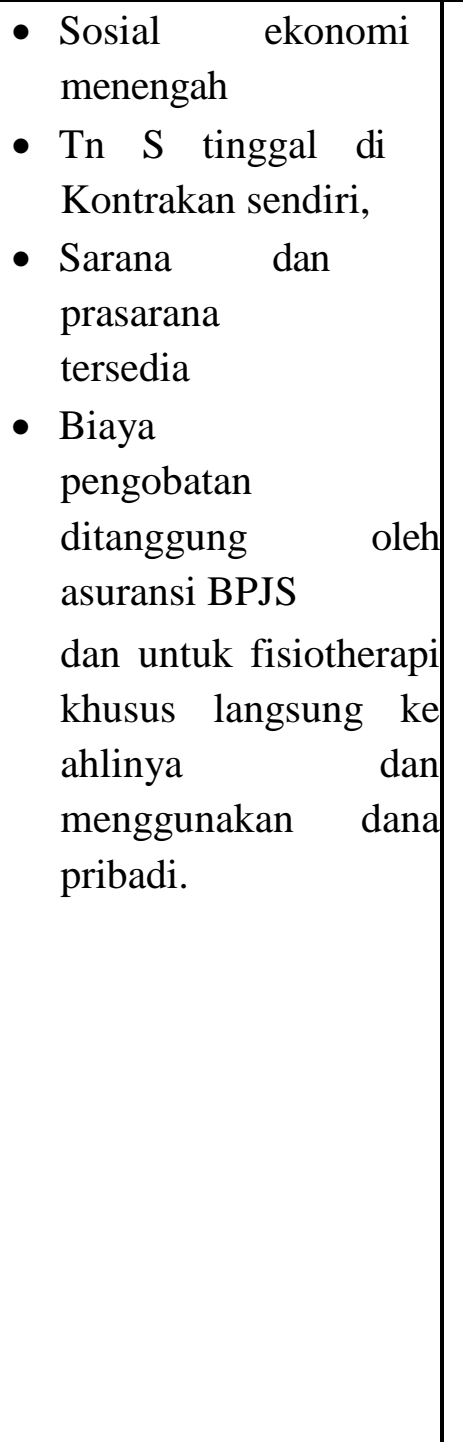 & $\begin{array}{l}\text { - Tn S percaya } \\
\text { bahwa petugas } \\
\text { kesehatan akan } \\
\text { membantunya } \\
\text { - Ny.E berharap } \\
\text { cepat sembuh } \\
\text { agar tidak } \\
\text { merepotkan } \\
\text { Keluarganya. } \\
\text { - Tn S selalu } \\
\text { berdoa untuk } \\
\text { kesembuhan } \\
\text { penyakitnya } \\
\text { Tn S yakin, bila } \\
\text { ia mengikuti } \\
\text { petunjuk dan } \\
\text { saran dari } \\
\text { petugas } \\
\text { kesehatan maka } \\
\text { ia akan cepat } \\
\text { sembuh } \\
\text { Tn S Tidak } \\
\text { yakin keluarga } \\
\text { mendukung } \\
\text { supaya lekas } \\
\text { sembuh. }\end{array}$ \\
\hline
\end{tabular}




\subsubsection{MEKANISME KOPIN}

\begin{tabular}{|c|c|}
\hline $\begin{array}{l}\text { HAL YANG } \\
\text { DILAKUKAN }\end{array}$ & ANALISA \\
\hline $\begin{array}{l}\text { - Tn S mengatakan bila ada masalah, maka ia akan membicarakan } \\
\text { - } \text { dengan Keluarga untuk mencari jalan keluarnya } \\
\text { - Tn S taat menjalankan ibadah sesuai dengan keyakinannya } \\
\text { - Tn S selalu berdoa } \\
\text { - Tn S Kurang mau bertemu orang banyak. }\end{array}$ & $\begin{array}{l}\text { - Konstruktif: } \\
\checkmark \text { Tn S mengatakan bila ada masalah Iya pendam sendiri. } \\
\checkmark \text { Bila sakit Tn S berobat ke pelayanan kesehatan } \\
\checkmark \text { Tn S taat menjalankan ibadah sesuai dengan } \\
\text { keyakinannya } \\
\checkmark \text { Tn S selalu berdoa agar bisa dapat kesembuhannya. } \\
\text { - Destruktif : - }\end{array}$ \\
\hline
\end{tabular}




\subsubsection{STATUS MENTAL}

\begin{tabular}{|l|l|}
\hline 1. Penampilan & Bersih, Rapi, Tidak tercium bau, Tn.S tampak gelisah \\
\hline 2. Pembicaraan & Berbicara dengan jelas \\
\hline 3. Aktifitas motoric & Saat di wawancara pasien tampak gelisah \\
\hline 4. Interaksi selama wawancara & Cukup kooperatif \\
\hline 5. Alam perasaan & Tn.S menunjukkan ekspresi takut dan khawatir \\
\hline 6. Afek & Sesuai dengan stimulus yang diberikan \\
\hline 7. Presepsi & Tn.S tidak mengalami ganguan presepsi dan sensori \\
\hline 8. Isi piker & Sebagian sudah sulit diingat karena umur sudah tua \\
\hline 9. Proses piker & Cukup Baik \\
\hline 10. Tingkat kesadaran & Compos mentis (Normal) \\
\hline 11. Daya ingat & Tn.S tidak mengingat beberapa kejadian dalam hidupnya \\
\hline 12. Kemampuan berhitung & Kemampuan berhitung cukup baik \\
\hline 13. Penilaian & $\begin{array}{l}\text { Tn.S belum mampu menyebutkan bagaimana Tn.S lekas } \\
\text { sembuh. }\end{array}$ \\
\hline 14. Daya titik diri & $\begin{array}{l}\text { Tn.S menyadari bahwa saat ini ia sedang sakit, Tn.S hanya } \\
\text { bisa berdoa supaya lekas sembuh agar tidak terus } \\
\text { merepotkan keluarganya. Tn.S menyadari ia memiliki istri, } \\
\text { anak-anak dan keluarga yang menyayanginya dan } \\
\text { mendukung kesembuhannya }\end{array}$ \\
\hline
\end{tabular}

Kesimpulan : Mental Status Examination (MSE) tidak ada masalah gangguan jiwa, gangguan

Tn.S lebih kepada Gangguan Mental Emosional (GME/Psikososial) 


\subsubsection{DIAGNOSA DAN TERAPI}

\begin{tabular}{|c|c|}
\hline DIAGNOSA KEPERAWATAN DAN TERAPI KEPERAWATAN & DIAGNOSA MEDIS \\
\hline $\begin{array}{l}\text { 1. Ketidakberdayaan } \\
\text { SP } 1 \text {. Bantu pasien mengenal ketidakberdayaan } \\
\text { a. } \\
\text { b. bantu pasien untuk mengidentifikasi dan menguraikan perasaannya } \\
\text { c. bantu pasien mengenal penyebab ketidakberdayaan } \\
\text { d. bantu klien menyadari perilaku akibat ketidakberdayaan } \\
\text { e. bantu klien untuk mengekspresikan perasaannya dan identifikasi area-area situasi kehidupannya yang } \\
\text { tidak berada dalam kemampuannya untuk mengontrol } \\
\text { f. identifikasi pemikiran yang negatif dan bantu untuk menurunkan melalui interupsi atau subtitusi e. bantu } \\
\quad \text { klien untuk mengidentifikasi faktor-faktor yang dapat berpengaruh terhadap ketidakberdayaannya } \\
\text { g. bantu pasien untuk meningkatkan pemikiran yang positive } \\
\text { h. evaluasi ketepatan persepsi, logika dan kesimpulan yang dibuat pasien j. identifikasi persepsi klien yang } \\
\text { tidak tepat, penyimpangan dan pendapatnya yang tidak rasional } \\
\text { 2. latih pasien mengembangkan afirmasi positive } \\
\text { SP } 2 \text { a. Latihan mengontrol perasaan ketidakberdayaan } \\
\text { b. melalui peningkatan kemampuan mengendalikan situasi yang masih bisa dilakukan pasien } \\
\text { c. Dukung kekuatan } 5 \text { kekuatan diri yang dapat di identifikasi oleh klien (misalnya klien masih mampu } \\
\quad \text { menjalankan peran sebagai ibu meskipun sedang sakit) } \\
\text { 3nsietas } \\
\text { Sp1: mendiskusikan penyebab,terjadinya proses terjadi, tanda gejala,akibat } \\
\text { Sp2 :melatih teknik releksasi fisik } \\
\text { Sp3:melatih mengatasi ansietas dengan distraksi dan hipnotis lima } \\
\text { Sp4 : melatih mengatasi ansietas memalui kegiatan spritual } \\
\text { Terapi Spesialis: CBT } \\
\text { Keputusasaan } \\
\text { SP 1 }\end{array}$ & Stroke \\
\hline
\end{tabular}


a. Bantu pasien mengenal keputusasaan:

b. bantu klien untuk mengidentifikasi dan menguraikan perasaan sedih/kesendirian/ keputusasaannya)

c. bantu klien mengenal penyebab putus asa

d. Diskusikan perbedaan antara perasaan dan pikiran klien terhadap kondisinya dengan kondisi real kondisi klien

e. bantu klien menyadari akibat putus asa

f. Dukung klien untuk mengungkapkan pengalaman yang mendukung pikiran, perasaan dan perilaku positif

g. Latih restrukturisasi pikiran melalui latihan berpikir positif dengan mengidentifikasi harapan dan penemuan makna hidup

SP 2

a. Diskusikan aspek positif diri sendiri, keluarga, dan lingkungan

b. Diskusikan kemampuan positif diri sendiri

c. Latih satu kemampuan positif

d. Tekankan bahwa kegiatan melakukan kemampuan positif berguna untuk menumbuhkan harapan dan makna hidup 


\section{IMPLEMENTASI TINDAKAN KPERAWATAN}

Tanggal : 08 november 2021

Jam : 10.00 -11.00 wib

SP 1

1. Bantu pasien mengenal ketidakberdayaan

a. bantu pasien untuk mengidentifikasi dan menguraikan perasaannya

b. bantu pasien mengenal penyebab ketidakberdayaan

c. bantu klien menyadari perilaku akibat ketidakberdayaan

d. bantu klien untuk mengekspresikan perasaannya dan identifikasi area-area situasi kehidupannya yang tidak berada dalam kemampuannya untuk mengontrol

e. identifikasi pemikiran yang negatif dan bantu untuk menurunkan melalui interupsi atau subtitusi e. bantu klien untuk mengidentifikasi faktor-faktor yang dapat berpengaruh terhadap ketidakberdayaannya

f. bantu pasien untuk meningkatkan pemikiran yang positive

g. evaluasi ketepatan persepsi, logika dan kesimpulan yang dibuat pasien

h. identifikasi persepsi klien yang tidak tepat, penyimpangan dan pendapatnya yang tidak rasional

2. latih pasien mengembangkan afirmasi positive SP 2

a. Latihan mengontrol perasaan ketidakberdayaan

b. melalui peningkatan kemampuan mengendalikan situasi yang masih bisa dilakukan pasien

c. Dukung kekuatan 5 kekuatan diri yang dapat di identifikasi oleh klien (misalnya klien masih mampu menjalankan peran sebagai ibu meskipun sedang sakit)

\section{EVALUASI}

S:

$\checkmark$ Klien mengatakan Ketidakberdayaanya : Berkurang setelah mengungkapkan perasaanya dan mengetahui penyebab ketidakberdyaannya

$\checkmark$ Klien kelihatannya sudah lebih tenang dan tidak khawatir

$\checkmark$ Klien menjelaskan apa yang telah disampaikan perawat

O :

$\checkmark$ Klien terlihat tampak tenang dan tidak gelisah

$\checkmark$ Klien dapat menjelaskan kembali penjelasan yang sudah diberikan

A: Ketidakberdayaan (+)

$\mathbf{P}$ :

\section{Evaluasi SP-1 dan SP-2}

$\checkmark$ Latihan cara mengatasi ketidakberdayaan :

a. Latih pasien mengembangkan afirmasi posituve

b. Latih memikirkan hal hal positif

c. Hipnotis 5 jari fokus pada hal-hal yang positif. 


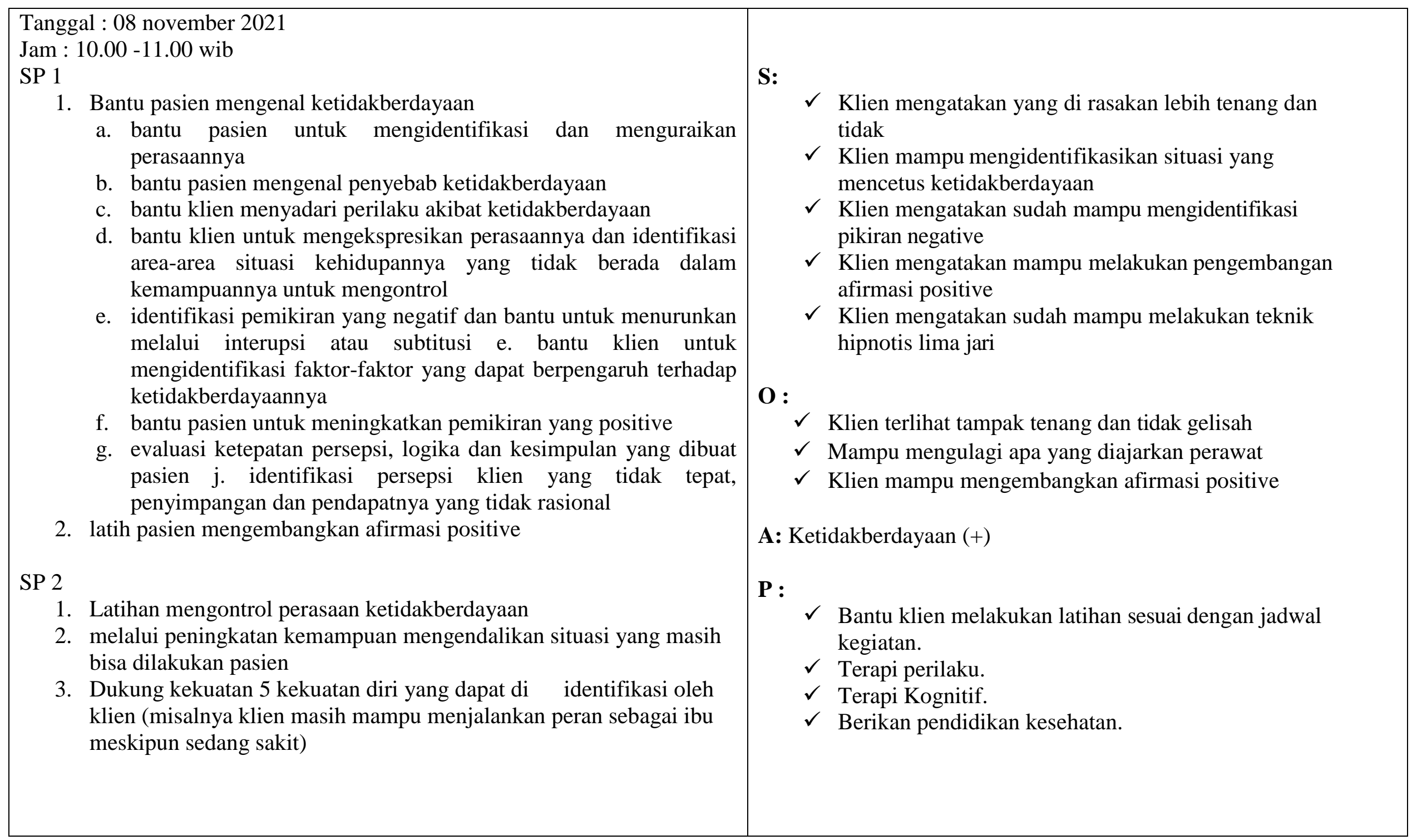




\section{BAB 4}

\section{PEMBAHASAN}

Setelah penulis melaksanakan asuhan keperawatan kepada Tn $\mathrm{S}$ dengan Ketidakberdayaan di jalan Simalingkar maka penulis pada BAB ini akan membahasan kesenjangan antara teoritis dengan tinjauan kasus. Pembahasan dimulai melalui tahapan proses keperawatan yaitu pengkajian, diagnosa keperawatan, perencanaan, pelaksanaan dan evaluasi.

\subsection{Tahap Pengkajian}

Selama pengkajian dilakukan pengumpulan data dari beberapa sumber, yaitu dari pasien dan tetangga sekitar. Maka penulis melakukan pendekatan kepada pasien melalui komunikasi teraupetik yang lebih terbuka membantu klien untuk memecahkan perasaannya dan juga melakukan observasi kepada pasien. Adapun upaya tersebut yaitu :

a. Melakukan pendekatan dan membina hubungan saling percaya diri pada klien agar klien lebih terbuka dan lebih percaya dengan menggunakan perasaan.

b. Mengadakan pengkajian klien dengan wawancara Dalam pengkajian ini, penulis tidak menemukan kesenjangan karena ditemukan hal sama seperti: diteori: Kecemasan adalah keadaan emosi dan pengalaman subyektif individu, tanpa objek yang spesifik karena ketidaktahuan dan mendahului pengalamanya yang baru seperti penyakitnya saat ini

\subsection{Tahap perencanaan}

Perencanaan dalam proses keperawatan lebih dikenal dengan rencana asuhan keperawatan yang merupakan tahap selanjutnya setelah pangkajian dan penentuan diagnosa keperawatan. Pada tahap perencanaan penulis hanya menyusun rencana tindakan keperawatan sesuai dengan pohon masalah keperawatan yaitu : Ketidakberdayaan. Pada tahap ini antara tinjauan teoritis dan tinjaun kasus tidak ada kesenjangan sehingga penulis dapat 
melaksanakan tindakan seoptimal mungkin dan didukung dengan seringnya bimbingan dengan pembimbing.

Secara teoritis digunakan cara strategi pertemuan sesuai dengan diagnosa keperawatan yang muncul saat pengkajian. Adapun upaya yang dilakukan penulis yaitu :

1. Klien mengungkapkan ketidakpastian tentang fluktuasi tingkat energi dan bersikap pasif.

2. Klien menunjukan sikap apatis, depresi terhadap perburukan fisik yang terjadi dengan mengabaikan kepatuhan pasien terhadap program pengobatan

3. Klien mengalami ketergantungan pada orang lain yang dapat mengakibatkan ititabilitas, ketidaksukaan, marah dan rasa bersalah. Klien tidak melakukan praktik perawatan diri ketika ditantang. Klien tidak ikut memantau kemajuan pengobatan. Klien menunjukan ekspresi ketidakpuasan terhadap ketidakmampuan melakukan aktivitas atau tugas sebelumnya. Klien menunjukan ekspresi keraguan tantang performa peran.

\subsection{Tahap Implementasi}

Pada tahap implementasi, penulis hanya mengatasi 1 masalah keperawatan yakni: diagnosa keperawatan Kecemasan merupakan keadaan emosi dan pengalaman subyektif induvidu,tanpa objek spesifik karena ketidaktahuan dan mendahului semua pengalaman yang di alami penyakit Stroke.

\subsection{Tahap Evaluasi}

Pada tinjauan teoritis evaluasi yang diharapkan adalah :

a. Membina hubungan saling percaya

b. Mengenali dan mengekspresikan emosinya

c. Mampu mengenal ansietas

d. Mampu mengatasi ansietas melalui teknik releksasi

e. Mampu mengatasi ansietas dengan terapi sugesti positif

f. Mampu mengatasi ansietas melalui hipnotis lima jari.

g. Mampu mengatasi ansietas melalui kegiatan spritual keagamaan. 


\section{BAB 5}

\section{PENUTUP}

\subsection{Kesimpulan}

Berdasarkan uraian pada pembahasan diatas, maka penulis dapat disimpulkan bahwa:

1. Pengkajian dilakukan secara langsung pada klien dan juga dengan menjadikan status klien sebagai sumber informasi yang dapat mendukung data-data pengkajian. Selama proses pengkajian, perawat mengunakan komunikasi terapeutik serta membina hubungan saling percaya antara perawat-klien. Pada kasus Ketidakberdayaan : Stroke

2. Diagnosa keperawatan yang utama pada klien dengan Ketidakberdayaan : Stroke

3. Perencanaan dan implementasi keperawatan disesuaikan dengan strategi pertemuan pada pasien.

4. Evaluasi keperawatan yang dilakukan menggunakan metode subyektif,obyektif,assessment dan planing.

\subsection{Saran}

1. Untuk institusi pendidikan

Diharapkan lebih meningkatkan pelayanan pendidikan yang lebih tinggi dan menghasilkan tenaga kesehatan yang profesional berwawasan global

2. Untuk keluarga

Diharapkan agar individu dan keluarga bisa mengerti tentang penyakit Stroke, dan meningkatkan perilaku hidup sehat dengan tujuan meningkatkan kualitas hidup. 


\section{DAFTAR PUSTAKA}

1. Hulu, E. K., \& Pardede, J. A. (2016). Dukungan Keluarga Dengan Tingkat Kecemasan Pasien Pre Operatif Di Rumah Sakit Sari Mutiara Medan. Jurnal Keperawatan, 2(1).

2. Pardede, J. A., Simanjuntak, G. V., \& Waruwu, J. F. A. P. (2020). Penurunan Tingkat Kecemasan Pasien HIV/AIDS melalui Terapi Hipnotis Lima Jari. Coping: Community of Publishing in Nursing, 8, 85-90.

3. Siregar, R. R. (2021). Studi Kasus Asuhan Keperawatan Psikososial Dengan Masalah Kecemasan Pada Penderita Hipertensi.

4. Pardede, J. A. (2020). Terapi Keluarga.

5. Pardede, J. A. (2020). Konsep Ketidakberdayaan.

6. Pardede, J. A. (2020). Kesiapan Peningkatan Perkembangan Anak Usia Sekolah.

7. Pardede, J. A., \& Simamora, M. (2020). Caring Perawat Berhubungan dengan Kecemasan Orangtua yang Anaknya Hospitalisasi. Jurnal Penelitian Perawat Profesional, 2(2), 171-178.

8. Nurhalimah. 2016. Keperawatan Jiwa. Jakarta: Kemenkes. Nurhalimah. 2017. Modul Ajar Konsep Keperawatan Jiwa .Jakarta: AIPViki Sutejo. 2017.

9. Burhanuddin. M., Wahiduddin., Jumriani. 2013. Faktor Risiko Kejadian Stroke Pada Dewasa Awal (18-40 Tahun) di Kota Makassar Tahun 2010-2012. Jurnal MKMI. dilihat 14 oktober 2016, www.repository.unhas.ac.id.

10. Pardede, J. A., Hutajulu, J., \& Pasaribu, P. E. (2020). Harga Diri dengan Depresi Pasien Hiv/aids. Jurnal Media Keperawatan: Politeknik Kesehatan Makassar, 11(01).

11. Pardede, J. A., Sitepu, S. F. A., \& Saragih, M. (2018). The Influence of Deep Breath Relaxation Techniques and Five-Finger Hypnotic Therapy on Preoperative Patient Anxiety. Journal of Psychiatry, 3(1), 1-8.

12. Venketasubramanian N, Yoon BW, Pandian J, Navarro JC. Stroke epidemiology in south, east, and south-east asia: a review. Journal of Stroke [Internet]. 2017 Sep 30;19(3): 286-94. Diunduh dari: http://dx.doi.org/10.5853/jos.2017.00234 Novermber 2017

13. Pardede, J. A., \& Simangunsong, M. M. (2020). Family Support With The Level of Preschool Children Anxiety in the Intravenous Installation. Jurnal Keperawatan Jiwa (JKJ): Persatuan Perawat Nasional Indonesia, 8(3), 223-234. https://doi.org/10.26714/jkj.8.3.2020.223-234

14. Handayani, F. Angka kejadian serangan stroke pada wanita lebih rendah daripada laki-laki. Jurnal Keperawatan Medikal Bedah [Internet]. 2013 Mei;1 (1) : 76-78. Diunduh dari: http://jurnal.unimus.ac.id/index.php/JKMB/article/view/942/994 Januari 2018

15. Wardhani, I.O. Martini, S. Hubungan antara karakteristik pasien stroke dan dukungan keluarga dengan kepatuhan menjalani rehabilitasi. Jurnal Berkala Epidemiologi [Internet]. 2015 Januari, 3(1): 24-34. Diunduh dari: https://ejournal.unair.ac.id/JBE/article/download/1310/1069 Januari $\underline{201}$

16. Marbun, A., Pardede, J. A., \& Perkasa, S. I. (2019). Efektivitas Terapi Hipnotis Lima Jari terhadap Kecemasan Ibu Pre Partum di Klinik Chelsea Husada Tanjung Beringin Kabupaten

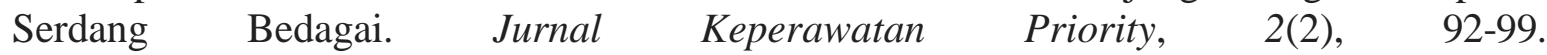
https://doi.org/10.34012/jukep.v2i2.568

17. Pardede, J. A., \& Tarigan, I. (2020). The Anxiety Level of Mother Presectio Caesar with Benson's Relaxation Therapy. Jendela Nursing Journal (JNJ), 4(1), 20-28. https://doi.org/10.31983/jnj.v4i1.5801 